Tabularasa: Jurnal Ilmiah Magister Psikologi, 1(1) 2019:1-9,
DoI:

\title{
Hubungan Self Efficacy dan Dukungan Sosial dengan Subjective Well- Being Korban Penyalahguna Napza di Balai Rehabilitasi Sosial Napza Insyaf Medan
}

\author{
The Relationship of Self Efficacy and Social Support with The \\ Subjective Well-Being of Drug Users in the Social Rehabilitation \\ Center of "INSYAF" Drug Users in Medan
}

\author{
Berliana Silalahi*, Abdul Munir \& Abdul Murad \\ Program Studi Magister Psikologi, Pascasarjana, Universitas Medan Area
}

\begin{abstract}
Abstrak
Penelitian ini bertujuan untuk melihat hubungan antara Self Efficacy dan Dukungan Sosial dengan Subjective WellBeing Penyalahguna NAPZA di Balai Rehabilitasi Sosial Korban Penyalahguna NAPZA “INSYAF” Medan. Metode penelitian menggunakan penelitian kuantitatif. Populasi penelitian sebanyak 180 orang penyalahguna NAPZA yang sedang menjalani rehabilitasi. Teknik pengambilan sampel menggunakan simple random sampling .dengan jumlah sampel sebanyak 80 orang penyalahguna NAPZA yang sedang menjalani rehabilitasi. Pengumpulan data menggunakan alat ukur skala Self Efficacy, skala Dukungan Sosial, skala Subjective Well-Being. Teknik analisis data data menggunakan analisis regresi linier berganda. Hasil penelitian menunjukkan ada hubungan yang signifikan positif antara Self Efficacy dengan Subjective Well-Being dengan koefisien korelasi (R) =0,681; sig <0.05, maka hipotesis diterima dengan sumbangan efektif sebesar 46,3\%. Ada hubungan yang signifikan positip antara Dukungan Sosial dengan Subjective Well-Being dengan koefisien korelasi (R) $=0.711$; Sig< 0,05, maka hipotesisi diterima dengan sumbangan efektif sebesar 50,5\%. Ada hubungan yang signifikan positif antara Self Efficacy dan Dukungan Sosial dengan Subjective Well-Being dengan koefisien korelasi (R) = 0,653; sig<0,05 maka hipotesis diterima dengan sumbangan efektif kedua variable bebas terhadap variable terikat sebesar $42,6 \%$. Ini berarti ada pengarug faktor lain sebesar 57\%, Faaktor lain itu bisa saja seperti Pendapatan, agama, hubungan sosial, budaya, Self Eksteem, dan sebagainya.
\end{abstract}

Kata kunci: Self Efficacy, Dukungan Sosial dengan Subjective Well Being

Abstract

This research aims to look at the relationship between Self Efficacy and Social Support with the Subjective Well-Being of Drug Users at the Social Rehabilitation Center for Victims of Drug Abuse "INSYAF" Medan. The research method uses quantitative research. The population of This research are 180 drug users who are undergoing rehabilitation. The sampling technique uses simple random sampling with a total sample of 80 .Data collection uses a Self Efficacy scale, a Social Support scale, a Subjective Well-Being scale. The Data analysis techniques using multiple linear regression analysis. The results showed there was a significant positive relationship between Self Efficacy and Subjective WellBeing with the correlation coefficient $(R)=0.681$; sig $<0.05$. The hypothesis is accepted with an effective contribution of 46.3\%. There is a positive significant relationship between Social Support and Subjective Well-Being with the correlation coefficient $(R)=0.711$; Sig $<0.05$. The hypothesis is accepted with an effective contribution of 50.5\%. There is a positive significant relationship between Self Efficacy and Social Support with Subjective Well-Being with the correlation coefficient $(R)=0.653$; sig<0.05. The hypothesis is accepted with the effective contribution of the two independent variables to the dependent variable by $42.6 \%$. This means that there is another factor of $57.4 \%$ of Subjective Well-Being. other factors could be income, religion, social relations, culture, self Eksteem, etc.

Keywords: Self Efficacy, Social Support with Subjective Well Being

How to Cite: Berliana Silalahi, Abdul Munir \& Abdul Murad, (2019). Hubungan Self Efficacy dan Dukungan Sosial dengan Subjective Well-Being Korban Penyalahguna Napza di Balai Rehabilitasi Sosial Napza Insyaf Medan. Tabularasa: Jurnal Ilmiah Magister Psikologi, 1(1) 2019: 1-9,

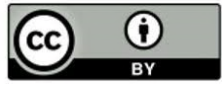




\section{PENDAHULUAN}

Dalam kurun waktu dekade terahir ini, masalah penyalahgunaan narkoba menjadi masalah yang sangat memprihatinkan, hal ini ditandai dengan bertambahnya jumlah penyalahguna atau pecandu narkoba di kalangan masyarakat dan banyaknya yang meninggal dunia akibat dari penyalahgunaan NAPZA. Dari hasil pengungkapan kasus tindak kejahatan yang telah dilakukan oleh aparat yang berkompeten, dan dari data korban penyalah guna NAPZA yang sedang menjalani NAPZA, mayoritas para korban penyalahguna NAPZA adalah di kalangan remaja dimana usia ini adalah usia produktif.

Data BNN menyebutkan bahwa jumlah penyalahguna narkoba di Indonesia diperkirakan telah mencapai sekitar 3,5 juta orang pada Tahun 2017, di mana 1,4 juta adalah pengguna biasa dan hampir satu juta telah menjadi pecandu narkoba. (BNN.2018). Lebih dari 90\% korban penyalahguna narkotik adalah remaja. Remaja cenderung menjadi sasaran utama pengedar obat/Zat adiktif, karena sifat remaja yang dinamis, energik, dan cenderung menempuh hidup yang berisiko, mudah dimanfaatkan oleh pengedar obat/zat adiktif untuk menjerumuskan remaja ke perbuatan negatif. Berdasrkan hasil survei pada populasi umum, penyalahgunaan narkoba pada generasi mudah masih lebih tinggi dari kelompok yang lebih tua. Usia awal (12-14 tahun) hingga akhir (15 - 17) sangat beresiko tinggi untuk memulai menggunakan narkoba, dan peningkatan penyalahgunaan tertingginya terjadi pada pemuda berusia 18-25 tahun (Puslidatin BNN, 2018).

Faktor keluarga merupakan salah satu penyebab terbesar terjerumusnya seseorang dalam penyalahgunaan NAPZA, keluarga broken Home dan kurangnya perhatian terhadap anak merupakan salah satu factor penyebab terjerumusnya seseorang terhadap penyalahgunaan NAPZA (Zahara, 2013; Siregar, 2018; Nainggolan, 2017). Badan Narkotika Nasional (BNN) memberikan penjelasan bahwa faktor-faktor yang menyebabkan seseorang terjerumus dunia narkoba terbagi dalam 3 bagian utama yaitu: 1. Factor diri (Pribadi) seseorang, yang itu factor, 2. Faktor Lingkungan. 3. Faktor Keluarga (Flavianus Darman, 2006).

Efek daripada penyalah gunaan narkoba memberikan dampak yang sangat negatif pada otak seperti stroke, dan kerusakan otak secara meluas yang dapat melumpuhkan segala aspek kehidupan pecandunya, penyalahgunaan narkoba juga dapat mengakibatkan perubahan fungsi otak sehingga menimbulkan permasalahan ingatan, permasalahan konsentrasi serta ketidakmampuan dalam mengambil keputusan.

Penyalahgunaan NAPZA menjadi ancaman besar dan akan sangat berpengaruh terhadap kehidupan bangsa dan negara pada masa mendatang, karena korban penyalahgunaan NAPZA adalah mayoritas pada generasi muda. Oleh karena itu Pemerintah berupaya mengatasinya dengan diterbitkannya Undang-Undang no. 35 Tahun 2009 tentang Narkotika yang mengamanatkan pencegahan, perlindungan, dan penyelamatan bangsa Indonesia dari penyalahgunaan narkotika serta menjamin pengaturan upaya rehabilitasi medis dan sosial bagi penyalah guna dan pecandu narkotika.

Kenyataan yang terjadi di masyarakat bahwa secara umum bahwa korban penyalahguna Napza tidak dengan kesadaran sendiri datang untuk menjalani rehabilitasi, akan tetapi dengan cara dipaksa oleh keluarga, baik itu dengan bantuan kepolisian, 
konselor, psikolog maupun dengan cara lain, padahal upaya rehabilitasi medis dan sosial bagi penyalahguna NAPZA sudah diatur dalam undang-undang. Program Rehabilitasi adalah pilihan yang baik untuk klien, khususnya mereka yang mempunyai kesulitan untuk menyesuaikan hidup tanpa menggunakan narkoba dan seringkali kambuh (Sumiati, 2009).

Dalam menjalani rehabilitasi korban penyalahguna NAPZA, tidak lepas dari berbagai kesulitaan-kesulitan, karena sejak awal menjalani rehabilitasi, para korban penyalahguna NAPZA adalah putus dengan zat, dengan demikian emosi pecandu narkoba ketika berbicara terkait peristiwa yang berhubungan dengan gejala putus zat atau proses relapse, individu merasakan adanya reaksi tubuh dan diakhiri dengan afek negatif seperti marah, sedih dan takut. Selain itu, para pengguna NAPZA juga sering diliputi oleh perasaanperasaan bersalah kepada diri, keluarga, masyarakat, komunitas maupun kepada Tuhan (Rosydah \& Nurdibyanandaru, 2010).

Menurut dr Hari 2019, tahapan putus zat kerap disebut sakau pada pengguna heroin. Ketika masuk rehabilitasi, pengguna yang tadinya menggunakan mendadak harus berhenti. Akibatnya akan timbul kondisi misal gejala depresi, cemas, gelisah, hingga muncul dorongan kuat untuk kembali menggunakan narkoba.

Selain tahapan putus zat, para korban penyalahguna NAPZA mau tidak mau harus melakukan penyesuaian diri dengan situasi yang baru. Pada saat pengguna memasuki panti rehabilitasi, masing-masing individu harus berkomitmen pada diri sendiri dan sesama anggota untuk memperbaiki dan meningkatkan mutu kehidupan di segala bidang, yaitu mental, spiritual, sosial dan jasmani, dengan demikian, hidup bersama, semangat persaudaraan, dan komitmen timbal-balik antara mereka dengan sendirinya menjadi model sekaligus metode penyembuhan bagi mereka masing-masing (Syafitri, 2013). Hal ini menjadi salah satu kesulitan yang harus dihadapai oleh korban penyalahguna NAPZA (Narkotika, Psikotropika dan Zat Adiktif) selama proses rehabilitasi.

Dengan kesulitan-kesulitan yang dihadapi tersebut, para korban penyalahguna NAPZA, harus mempunyai kekuatan untuk tetap mampu bertahan dalam menghadapi, mengatasi, mempelajari kesulitan dalam hidup tersebut dinamakan resilience (Grotberg, 2000 dalam Pertiwi, 2011). Resilience merupakan kemampuan untuk pulih dari krisis dan mengatasi tantangan hidup (Walsh, 2006).

Penyalah guna NAPZA yang memiliki tingkat resilience yang tinggi mampu dan memiliki kekuatan untuk mempertahankan diri bersih dari NAPZA, dan memiliki daya tahan dalam menjalani serangkaian kegiatan rehabilitasi (Pertiwi, 2011). Resilience yang merupakan kemampuan individu dalam melakukan penyesuaian dengan masa-masa yang sulit dapat mempengaruhi Subjective well being (Diener et al, 2005). Untuk mencapai kesejahteraan (well being) dibutuhkan suatu kemampuan yang disebut resilience (Kemala, 2014). Faktor-faktor yang turut mempengaruhi Subjective well Being adalah Self Efficacy dan Dukungan Sosial, (Tarigan, 2018; Wati \& Cut, 2010; Hamdani, dkk., 2015).

Diener (2003 dalam Suyasa 2011) mendefinisikan well being sebagai kondisi pada saat individu mengalami kepuasan pada berbagai aspek kehidupan atau pada berbagai peristiwa, pada saat individu tidak memiliki perasaan cemas, atau hanya memiliki tingkat kecemasan yang rendah, pada saat individu tidak berada dalam kondisi depresi, dan pada 
saat individu mengalami emosi-emosi positif (Zahara, 2013; Siregar, 2018; Nainggolan, 2017)

Individu dikatakan memiliki subjective well being (Kesejahteraan Subjektif) tinggi jika mengalami kepuasan hidup, sering merasakan kegembiraan, dan jarang merasakan emosi yang tidak menyenangkan seperti kesedihan atau kemarahan. Sebaliknya, individu dikatakan memiliki subjective well being rendah jika tidak puas dengan kehidupannya, mengalami sedikit kegembiraan lebih sering merasakan emosi negatif seperti kemarahan atau kecemasan. Diener et al, 1999 dalam Eid dan Larsen (2008).

Kesejahteraan merupakan tujuan utama dari eksistensi hidup manusia. Setiap orang juga memiliki harapan-harapan yang ingin dicapai guna pemenuhan kepuasan dalam kehidupannya. Aristoteles (dalam Ningsih, 2013) Tidak terkecuali, hal itupun diinginkan oleh para korban penyalah gunaan NAPZA. Akan tetapi, para korban penyalahgunaan NAPZA yang sedang mengikuti rehabilitasi, terkadang lupa melakukan evaluasi dalam hidupnya, sehingga kurang melakukan persiapan untuk menghadapi proses rehabilitasi yang akan dia jalani, dengan demikian menimbulkan perasaan rendah diri, tidak terima dengan keadaan dan merasa terbuang, hingga menimbulkan rasa marah pada dirinya.

Keberhasilan pemulihan bagi mantan penyalahguna narkoba dari ketergantungan dipengaruhi oleh berbagai faktor seperti faktor predisposisi (misalnya karakteristik personal/ kepribadian), faktor kontribusi (misalnya keluarga) dan faktor pencetus (seperti teman sebaya, lingkungan dan narkoba itu sendiri) (Hawari, 2006). Dari faktor personal selain kepribadian juga terdapat motivasi atau kekuatan untuk pulih. Kekuatan dimana mereka bisa lepas dan bersih dari NAPZA dan bertahan agar tidak relapse, mempunyai keyakinan diri serta dapat menjalani serangkaian program rehabilitasi agar mereka dapat melanjutkan hidupnya, sekaligus mampu memiliki pandangan yang positif terhadap kehidupan diri mereka sendiri (Pertiwi, 2011). Dari faktor personal selain kepribadian juga terdapat motivasi atau kekuatan untuk pulih (Zuraida, 2015; Hardjo, 2015; Misnita, 2015).

Keyakinan diri inilah yang disebut Efikasi diri, yaitu keyakinan seseorang dalam kemampuannya untuk melakukan suatu bentuk kontrol terhadap keberfungsian orang itu sendiri dan kejadian dalam lingkungan (Bandura, 2001). Manusia yang mempunyai penerimaan diri yang tinggi akan mampu mengubah situasi dalam lingkungannya dan akaan lebih mudah untuk meraih kesuksesan disbanding dengan orang yang penerimaan diri yang rendah. Dengan memiliki efikasi tinggi akan menghasilkan emosi keyakinan diri yang tinggi yang akan membawanya menjalani kehidupan dengan tetap ceria seperti mau berbagi terutama pada sesama mantan korban penyalahguna NAPZA,

Dukungan sosial dari keluarga, baik dukungan berupa perhatian, pemberian saran, materi, semangat dan lainnya dapat membantu dalam menjalani proses penyembuhan pada korban penyalahguna NAPZA karena dengan dukungan sosial keluarga, korban penyalahguna NAPZA akan merasa diperhatikan dan menghilangkan perasaan ditinggalkan oleh keluarga. Dukungan sosial terutama dari keluarga juga menjadi hal penting dalam pemulihan mantan pecandu narkoba, agar tidak kembali menggunakan narkoba dikemudian hari. Pemberian dukungan dari keluarga diharapkan dapat membantu efektivitas proses pemulihan (Retno, 2003). 


\section{METODE PENELITIAN}

Metode yang digunakan dalam penelitian ini adalah metode korelasi. Hal ini karena peneliti bertujuanuntuk mengetahui hubungan Self Efficacy dan Dukungan Sosial dengan Subjective Well Being korban penyalahguna NAPZA di Balai Rehabilitasi Sosial NAPZA "INSYAF" Medan.

Populasi dalam penelitian ini adalah seluruh korban penyalahguna NAPZA yang sedang menjalani rehabilitasi di Balai Sosial NAPZA “INSYAF" Medan dengan jumlah 180 orang, sedangkan yang menjadi sampel penelitian adalah berjumlah 90 orang yaitu $1 / 2$ dari jumlah keseluruhan.

Alat ukur yang digunakan dalam penelitian ini adalah kuesioner Subjective Well Being (SWB), Self efficacy dan dukungan sosial, menggunakan skala Likert dengan pilihan jawaban serta skor yang mempunyai 4 pilihan skala jawaban, yakni Sangat Setuju, Setuju (S), Tidak setuju (TS), Sangat Tidak Setuju (STS). Pemberian skor untuk skala ini bergerak dari 4 sampai 1 untuk aitem vavorable sedangkan untuk aitem tidak favourable bergerak dari 1 sampai 4. Untuk kuesener Subjective Well-Being sebanyak 36 Aitem, Selff Efficacy sebanyak 25 aitem, Hasil ujicoba alat ukur untuk self efficacy berdasarkan jumlah 25 butir aitem, diketahui terdapat 3 aitem yang dinyatakan gugur karena daya beda aitem lebih kecil dari 0.3 yakni pada pada nomor 8, 15 dan 19. Butir yang valid memiliki koefisien korelasi aitem total $\left(\mathrm{rbt}\right.$ ) antara 0,84 sampai $\mathrm{r}_{\mathrm{bt}}$ 0.711. Hasil ujicoba Selanjutnya berdasarkan hasil uji coba skala Dukungan Sosial yang berjumlah 40 butir, diketahui bahwa terdapat 2 butir pernyataan yang gugur karena daya beda aitem lebih kecil dari 0.3 yakni pada nomor 14 dan 39. Aitem yang valid sebanyak 38 butir karena daya beda aitem lebih besar dari 0.3. Butir yang valid memiliki koefisien korelasi aitem total ( $\mathrm{r}_{\mathrm{bt}}$ ) antara 0.328 sampai $\mathrm{r}_{\mathrm{bt}}$ 0.727. Dukungan Sosial yang berjumlah 40 butir, diketahui bahwa terdapat 2 butir pernyataan yang gugur karena daya beda aitem lebih kecil dari 0.3 yakni pada nomor 14 dan 39. Aitem yang valid sebanyak 38 butir karena daya beda aitem lebih besar dari 0.3. Butir yang valid memiliki koefisien korelasi aitem total ( $\mathrm{rbt}_{\mathrm{bt}}$ antara 0.328 sampai rbt 0.727 . Kemudian dari hasil uji reliabilitas dari butir pernyataan yang valid dengan menggunakan rumus Cronbach's Alpha, pada tabel 4.7 diketahui bahwa skala Dukungan Sosial dinyatakan reliabel, dimana nilai koefisien $r_{t t}=0.897$. Dari hasil ini maka Dukungan Sosial dapat digunakan pada saat yang lain. Sedangkan hasil uji coba skala Subjective Well Being yang berjumlah 36 butir aitem, diketahui bahwa terdapat 4 butir aitem pernyataan yang gugur karena daya beda aitem lebih kecil dari 0.30 yakni pada pada nomor 13, 17, 19 dan 29. Aitem yang valid sebanyak 32 butir karena daya beda aitem lebih besar dari 0,30. Butir yang valid memiliki koefisien korelasi item total ( $\mathrm{rbt}$ ) antara 0,322 sampai rbt 0.774 . Kemudian dari hasil uji reliabilitas dari butir pernyataan yang valid dengan menggunakan rumus Cronbach's Alpha, pada tabel 4.9 diketahui bahwa skala Subjective Well Being dinyatakan reliabel, dimana nilai koefisien $\mathrm{r}_{\mathrm{tt}}=0.845$. Dari hasil ini maka skala Subjective Well Being dapat digunakan pada saat yang lain.

Data yang diperoleh dalam penelitian ini diolah dengan menggunakan pearson product moment dengan menggunakan spss for windows versi 20.0. Sebelum data data terkumpul dianalisa, terlebih dahulu dilakukan uji asumsi yang meliputi uji normalitas 
dan linieritas. Uji normalitas dilakukan dengan menggunakan Kolmogorov-Smirnov Test. Sebagai kriterianya apabila $\mathrm{p}>0.050$ maka sebarannya dinyatakan normal, sebaliknya apabila p < 0.050 sebarannya dinyatakan tidak normal (Hadi dan Pamardiningsih, 2000). Hasil untuk Subjective Well Being diperoleh hasil normalitas variabel Subjective Well Being (Y) sebesar 0,746 dimana $\mathrm{p}>0,050$ dapat disimpulkan bahwa variabel Subjective Well Being berdistribusi normal, kemudian untuk variabel Self Eficacy ( $\mathrm{X}_{1}$ ) sebesar 0,057 dimana $\mathrm{p}>$ 0,05 maka dapat disimpulkan bahwa variabel Self Eficacy berdistribusi normal, selanjutnya untuk variabel Dukungan Sosial $\left(\mathrm{X}_{2}\right)$ sebesar 0,785 dimana $\mathrm{p}>0,05$ maka dapat disimpulkan bahwa variabel Dukungan Sosial berdistribusi normal.

\section{HASIL DAN PEMBAHASAN}

\section{Hubungan antara Self Efficacy dengan Subjective Well-Being (R)}

Hubungan antara Self Efficacy dengan Subjective Well-Being (R) sebesar 0,681 menunjukkan hubungan yang cukup kuat diantara keduanya. Arah hubungan yang positif (tanda positif pada angka 0,681) menunjukkan bahwa semakin tinggi Self Efficacy akan membuat Subjective Well Being semakin tinggi, demikian pula sebaliknya jika semakin rendah Self Efficacy maka akan membuat Subjective Well Being juga rendah. Angka ${ }^{2}$ sebesar 0,463 disebut koefisien determinasi, menunjukkan bahwa Self Eficacy memiliki kontribusi sebesar 46,3\% dalam menjelaskan Subjective Well Being, sementara sisanya dipengaruhi oleh variabel lain. Tingkat signifikansi koefisien korelasi satu sisi dari output (diukur dari probabilitas $\mathrm{p}$ ) menghasilkan angka 0,000. Oleh karena probabilitas $\mathrm{p}<0,05$ hal ini berarti korelasinya bersifat signifikan.

Keberhasilan pemulihan bagi mantan penyalahguna narkoba dari ketergantungan ketergantungan dipengaruhi oleh berbagai faktor seperti faktor predisposisi (misalnya karakteristik personal/ kepribadian), faktor kontribusi (misalnya keluarga) dan faktor pencetus (seperti teman sebaya, lingkungan dan narkoba itu sendiri) (Hawari, 2006). Dari faktor personal selain kepribadian juga terdapat motivasi atau kekuatan untuk pulih. Kekuatan dimana mereka bisa lepas dan bersih dari NAPZA dan bertahan agar tidak relapse, mempunyai keyakinan diri serta dapat menjalani serangkaian program rehabilitasi agar mereka dapat melanjutkan hidupnya, sekaligus mampu memiliki pandangan yang positif terhadap kehidupan diri mereka sendiri (Pertiwi, 2011). Dari faktor personal selain kepribadian juga terdapat motivasi atau kekuatan untuk pulih.

Keyakinan seseorang adalah landasan dari hidup manusia. Manusia dengan efficacy (Penerimaan) tinggi yakin bahwa mereka dapat melakukan sesuatu yang mempunyai potensi untuk dapat mengubah kejadian di lingkungannya dan akan lebih mungkin bertindak serta lebih mungkin untuk menjadi sukses daripada manusia yang mempunyai efficacy (Penerimaan) rendah. (Bandura, 2001).

Dengan memiliki efikasi tinggi akan menghasilkan emosi keyakinan diri yang tinggi yang akan membawanya menjalani kehidupan dengan tetap ceria seperti mau berbagi terutama pada sesama mantan korban penyalahguna NAPZA, Kebahagiaan masingmasing orang inilah yang disebut sebagai subjective well Being yaitu kepuasan hidup dan evaluasi terhadap domain-domain kehidupan yang penting seperti pekerjaan, kesehatan dan hubungan (Diener, 2008). 


\section{Hubungan antara Dukungan Sosial dengan Subjective well Being}

Hubungan antara Dukungan Sosial dengan Subjective well Being (R) sebesar 0,711 menunjukkan hubungan yang cukup kuat diantara keduanya. Arah hubungan yang positif (tanda positif pada angka 0,711) menunjukkan bahwa semakin tinggi Dukungan Sosial akan membuat Subjective Well Being semakin tinggi, demikian pula sebaliknya jika semakin rendah Dukungan Sosial maka akan membuat Subjective Well Being juga rendah. Angka $\mathrm{R}^{2}$ sebesar 0,505 disebut koefisien determinasi, menunjukkan bahwa Dukungan Sosial memiliki kontribusi sebesar 50,5\% dalam menjelaskan Subjective Well Being, sementara sisanya dipengaruhi oleh variabel lain. Tingkat signifikansi koefisien korelasi satu sisi dari output (diukur dari probabilitas p) menghasilkan angka 0,000. Oleh karena probabilitas $\mathrm{p}<0,05$ hal ini berarti korelasinya bersifat signifikan.

aluasi yang dilakukan seseorang terhadap kehidupannya. Evaluasi tersebut bersifat kognitif dan afektif. Evaluasi yang bersifat kognitif meliputi bagaimana seseorang merasakan kepuasan dalam hidupnya. Adapun domain kepuasan, seperti kesehatan fisik dan mental, pekerjaan, waktu luang, hubungan sosial, dan keluarga (Diener, 2005) Evaluasi yang bersifat afektif meliputi seberapa sering seseorang merasakan emosi positif dan emosi negative, emosi positif termasuk smile/laugh dan enjoyment. Sedangkan emosi negatif termasuk worry, sadness, depression, dan anger (Tay \& Diener, 2011). Hubungan Self-Efficacy dengan Subjective Well Being (SWB) secara garis besar membuktikan bahwa Self-Efficacy, mempengaruhi kesehatan, prestasi dan kesuksesan beradaptasi serta memberikan kontribusi terhadap kepuasan hidup dan kesejahteraan sisiwa (Bandura, 1977 dalam Pramudita, 2015).

Dukungan sosial akan mempengaruhi kepuasan seperti rasa bahagia dan lebih sedikit merasakan kesedihan karena adanya dukungan sosial akan membuat seseorang merasa nyaman dan hal tersebut akan berkontribusi terhadap afek positif (Diener \& Seligman, 2004). Selain itu juga diketahui bahwa, orang kolektivistik lebih sering berinteraksi dengan orang lain jika dibandingkan dengan orang individualistis. Hal ini dilakukan dengan tujuan untuk mengevaluasi kehidupannya. Sehingga dukungan sosial dianggap relevan dengan kepuasan hidup, karena dukungan sosial pada budaya dapat memiliki pengaruh yang luas pada nilai-nilai dan tujuan masyarakat (Diener, 2000).

Hasil Penelitian ini mendukung penelitian lain yang dilakukan oleh Anaztasia Alsarida, Susandari dengan judul Hubungan Dukungan Sosial Dengan Subjective Well Being Pada Anggota Komunitas Mualaf Di Bandung dengan jumlah ampel sebanyak 29 orang di komuninas Mualaf Bandung. Berdasarkan hasil penelitian yang telah dilakukan, maka dapat ditarik kesimpulan sebagai berikut: 1. Terdapat hubungan positif antara Dukungan Sosial dengan Subjective Well-Being aspek Kognitif dan Afek Positif pada anggota komunitas mualaf $\mathrm{X}$ di Bandung., Terdapat hubungan negatif antara Dukungan Sosial dengan Subjective WellBeing aspek Kognitif. Hubungan antara Dukungan Aspek Instrumen dengan Subjective WellBeing aspek Kognitif menunjukan nilai koefisien korelasi tertinggi dari seluruh aspek yang diukur. 


\section{SIMPULAN}

Hubungan antara Self Efficacy dengan Subjective Well-Being (R) sebesar 0,681 menunjukkan hubungan yang cukup kuat diantara keduanya. Arah hubungan yang positif (tanda positif pada angka 0,681) menunjukkan bahwa semakin tinggi Self Efficacy akan membuat Subjective Well Being semakin tinggi, demikian pula sebaliknya jika semakin rendah Self Efficacy maka akan membuat Subjective Well Being juga rendah.

Angka $\mathrm{R}^{2}$ sebesar 0,463 disebut koefisien determinasi, menunjukkan bahwa Self Eficacy memiliki kontribusi sebesar 46,3\% dalam menjelaskan Subjective Well Being, sementara sisanya dipengaruhi oleh variabel lain. Tingkat signifikansi koefisien korelasi satu sisi dari output (diukur dari probabilitas p) menghasilkan angka 0,000. Oleh karena probabilitas $\mathrm{p}<0,05$ hal ini berarti korelasinya bersifat signifikan.

Hubungan antara Dukungan Sosial dengan Subjective Well-Being (R) sebesar 0,711 menunjukkan hubungan yang cukup kuat diantara keduanya. Arah hubungan yang positif (tanda positif pada angka 0,711) menunjukkan bahwa semakin tinggi Dukungan Sosial akan membuat Subjective Well Being semakin tinggi, demikian pula sebaliknya jika semakin rendah Dukungan Sosial maka akan membuat Subjective Well Being juga rendah

\section{DAFTAR PUSTAKA}

Agbaria, Q. Ronen, T., \& Hamama, L., (2012). The link between developmental components (age and gender),need to belong and resources of self-control and feelings of happiness, and frequency of symptoms among Arab adolescents in Islael. Children and Youth Services Reviw, 34,2018 - 2027

Ali, M, \& Asrori, M, (2010). Psikologi Remaja: Perkembangan peserta didik. Jakarta: Bumi Aksara

Alsarida, Anaztasia, Susandari. (2019). Hubungan Dukungan Sosial Dengan Subjective Well Being Pada Anggota Komunitas Mualaf Di Bandung. Jurnal.

Anwar, A.I.D., (2009). Hubungan Antara Self-Efficacy Dengan Kecemasan Berbicara di Depan Umum pada Mahasiswa Fakultas Psikologi Universitas Sumatera Utara.Medan. Universitas Sumatera Utara

Apollo dan Cahyadi, (2012). Konflik Peran Ganda Perempuan Menikah Yang Bekerja Ditinjau dari Dukungan Sosial Keluarga dan Penyesuaian diri. Widya Warta. No.02.ISSN 0854-1981

Arikunto, S, (2006). Prosedur Penelitian Suatu Pendekatan Praktik. Jakarta: Penerbit PT Rineka Cipta

Balai Pustaka, (2008). Kamus Besar Bahasa Indonesia.Gramedia Penerbit Buku Utama

Bandura, A., (2006). Article of guide for Contructing Self Efficacy Scales.by Information Age Publishing

Baron, R.A. \& Byrne, D, (2004). Psikologi Sosial Jilid I. Jakarta: Erlangga

Ben-Zur, H., (2003). Happy adolscents: The link between subjective well-being, internal resources, and parental factors. Journal of youth and Adolescenc, 32(2), 67-69

Brown, S. L., Nesse, R.M., Vinokur, A.D., \& Smith, D. M., (2003). Providing social support may be more beneficial than receiving it result from a prospective study of mortality. Psychological Science 14(4), 320-327.

Chen, Sm, Chen, X., Chen, Q., \& Shevlin, T., (2010). Are Family Firm More Tax Aggressive Than Non-Family Firms? Journal of Financial Economic,95:41-61.

Cohen, S., \& Syme, S.L. (1985). Social Support \& Health. Florida: Academic Press Inc.

Compton, William C., (2005). An Introduction to Positive Psychology. Belmont: Thomson Wadsworth.

Darman, F. (2006). Mengenal jenis dan efek buruk narkoba, Tangerang. Visi Media. Fauziannisa Maindra, Mareyke Maritje

Darman, Flavianus. (2006).Mengenal Jenis dan Efek Buruk Narkoba. Visimedia, Jakarta.

Departemen Pendidikan Nasional. (2002). Kamus Besar Bahasa Indonesia, Jakarta: Balai Pustaka.

Dian Ayusta Putri , Veronika Suprapti . (2014). Journal of.unair/ac.ad. subjective well being pada Mahasiswa Baru Politeknik Elektronika Negeri Surabaya (PENS) yang Kos

Diener, E. (Ed) (2009) The Science of Subjective well being: The Collected works of Ed Diener. Netherlands: Springer

Diener, E., \& Lucas, R. Shigehiro Oishi, (2003). Subjective Well Being. New York. The Science Happines and Life Satisfaction 
Diener, E., \& Lucas, R.E., \& Oishi, S. (2002). Subjective Well-being The Science of happiness and life satisfaction. In C.R. Snyder \& S.J. Lopez (Eds), The hand book of positive psychology. (pp. 63-73). New York: Oxford University Press

Diener, Ed (1994) Assesing Subjective well being. Progress and Opportunitis social Indicators Research. Journal Psychology,31 (2), 103 - 57

Diener, Ed (2002) Finding On Subjective Well-Being and Their Implication for Empowerment. Washington DC: University of Illioni

Eid, M. \& Larsen, R.J. (2008). The science of Subjective Well-Being. New York: The Guilford Pres.

Elni, Nef. (2018) Hubungan Pengetahuan dan Dukungan Keluarga dengan Perilaku Penyalahgunaan Napza di Kelas IIA Lembaga Pemasyarakatan Jambi. Jurnal Ilmiah Universitas Batanghari Jambi Vol.18 No.2 Tahun 2018

Feist, J \& Feist, G. J., (2010). Teori Kepribadian, edisi 7. Jakarta: Salemba Humanika

Gatari, E, (2008). Hubungan antara perceived social support dengan subjective well-being pada Ibu Bekerja. Artikel Psikologi. Jakarta: Program Studi Psikologi Universitas Indonesia

Ghuron, M. N. dan Risnawati, R. (2011). Teori-teoriPsikologi. Jogyakarta: Ar-Ruzz Media

Hamdani, R., Lahmuddin L., \& Aziz, A., (2015), Hubungan antara Dukungan Sosial dan Kecerdasan Emosional dengan Self-Regulated Learning Siswa. Analitika: 7 (2): 105-117

Hardjo, S., \& Eryanti N., (2015), Hubungan Dukungan Sosial dengan Psychological Well-Being pada Remaja Korban Sexual Abuse, Analitika: 7 (1): 12-19

Indriyani, P. A. (2013). Model Pengembangan Subjective well being Pada Masa Pensiun. Jurnal IlmiahMahasiswa Universita Surabaya Vol.2 No.1

Isnawati, D. \& Suhariadi, F, (2013). Hubungan Antara Dukungan Sosial dengan Penyesuaian diri masa persiapan pension pada karyawan PT. Pupuk Kaltim. Jurnal Psikologi Industri dan Organisasi. No. 1. Vol. 2.1-6

King, Laura A., (2010). Psikologi Umum Sebuah Pandangan Apresiatif. Jakarta: Salemba Humanika

Komalaari, Wuri, (2018). Hubungan Dukungan Keluarga dengan Motivasi Pasien NAPZA di Lembaga Permasyarakatan Muaro Padang. Journal.Vol. XII Jilid I No.79

Maryati, I., (2008). Hubungan Antara Kecerdasan Emosi dan Keyakinan Diri (Slf-Efficacy) Dengan Kreativitas Pada Siswa Akseleeasi. Surakarta: Universitas Muhammadiyah Surakarta

Maryati, I., (2008). Hubungan Antara Kecerdasan Emosi dan Keyakinan Diri (Slf-Efficacy) Dengan Kreativitas Pada Siswa Akseleeasi. Surakarta: Universitas Muhammadiyah Surakarta

Misnita, H., Lahmuddin L., \& Azhar A., (2015), Hubungan Keyakinan Diri dan Dukungan Sosial dengan Penyesuaian Diri Mahasiswa, Analitika: 7 (1): 31-38

Nainggolan, W.S.. Chandra, A., \& Sembiring, S.A. 2017. Hubungan Dukungan Sosial dengan Harga Diri pada Mantan Pengguna Narkoba, Jurnal Diversita, 3 (2): 94-100

Nawangsih, S.K. \& Sari, P.R. (2016). Stres pada mantan pengguna narkoba yang menjalani Rehabilitasi. Journal UNDIP.ac.id/index/php/psikologi/article

Nayana, F.N. (2013) .Kefungsian Keluarga Dan Subjective Well-Being pada Remaja. Journal Psikologi.Vol. 01, No.02, Agustus 2013

Rosyidah, R., \& Nurdibyanandaru, D. (2010) Dinamika emosi pecandu narkotika dalam masa pemulihan. Fakultas Psikologi Universitas Airlangga Surabaya

Siregar, N. (2018). Kualitas Hidup Wanita Menopause Ditinjau dari Dukungan Sosial di Kelurahan Sempakata Padang Bulan Medan. JURNAL DIVERSITA, 4 4(1), doi:https://doi.org/10.31289/diversita.v4i1.1566

Taira, W, (2013). Hubungan antara Strategi Coping dengan Self-efficacy pada Penyalahguna Narkoba pada Masa Pemulihan. Jurnal Jurnal Psikologi Kepribadian dan Sosial Vol.02 No. 03.

Tarigan, M. (2018). Hubungan Dukungan Sosial dengan Subjective Well-Being pada Remaja yang Memiliki Orangtua Tunggal. JURNAL DIVERSITA, 4(1), 1-8. doi:https://doi.org/10.31289/diversita.v4i1.1565

Wati S, P. \& Cut M., (2010), Hubungan antara Dukungan Sosial Keluarga dan Self Efficacy dengan Kemandirian Belajar pada Siswa SMKN 2 Medan, Analitika: 2 (2): 45-54

Widhiastuti, H. (2010). Mengelola stres menjadi suatu kekuatan. Semarang: University Press

Zahara, F,, \& Cut M., (2013) Hubungan Dukungan Sosial Orangtua dan Motivasi Belajar dengan Kemandirian Belajar, Analitika: 5 (1): 8-16

Zuraida, Kaiman T, \& Sri S, (2015), Hubungan Kecerdasan Emosional dan Dukungan Sosial Keluarga dengan Burnout, Analitika: 7 (2): 141-149 